\title{
el-Qist
}

\section{Analisis Penerapan Sistem Informasi Manajemen UMKM pada Operasional Kantin Ilmu di Yayasan Perkumpulan Kanjeng Sepuh}

\author{
Muhammad Yusuf Aria Widjaja \\ Sekolah Tinggi Ekonomi Islam Kanjeng Sepuh Gresik \\ Email:yusuf@steikassi.ac.id \\ Yusda Auliyah Anifatin \\ Sekolah Tinggi Ekonomi Islam Kanjeng Sepuh Gresik
}

\begin{abstract}
Management information system is a means for operations that can support business wheels. Business units with a scale of small, medium to corporate level can make it easier to run by implementing the existence of this system to achieve all business developments. The research objective is to study the implementation and development of information systems experiments in the operational management of Kanjeng Sepuh Sidayu Gresik Canteen. The research method used is descriptive qualitative by triangulating data sources through interviews and literature studies. Researchers also use SDLC (System Development Lifecycle or System Development Lifecycle) in deepening data development methods. The application of SDLC can unravel the challenges, changes and development that can be realized by this business unit. The application of information systems in "Kantin Ilmu" uses simple software in inputting data. However, by changing conventional transactions towards the present era, commitment and management integration are needed in order to produce conducive complications. Enabling, participating the "Kantin Ilmu" in improving the welfare of small and medium scale businesses in the north coast region can be fully realized. Through the proposed system, stakeholders can find out profit and loss periodically. This will help the business owner entity in the strategies used to achieve the vision and mission.
\end{abstract}

Keywords: Management Information Systems; SDLC; UMKM; Canteen Development.

\begin{abstract}
Abstrak: Sistem informasi manajemen merupakan suatu sarana bagi operasional usaha yang dapat menjadi pendukung suatu perputaran roda bisnis. Unit usaha dengan skala bisnis kecil, menengah hingga setingkat perusahaan dapat mudah menjalankan dengan menerapakan adanya sistem ini untuk mencapai suatu perekembangan bisnis. Tujuan penelitian adalah untuk mengetahui upaya penerapan dan perkembangan sistem informasi pada operasional manajemen Kantin Ilmu Kanjeng Sepuh Sidayu Gresik. Metode penelitian yang digunakan adalah deskriptif kualitatif dengan melakukan trianggulasi sumber data melalui wawancara dan studi literasi.


Peneliti juga menggunakan SDLC (System Development Life Cycle atau Siklus Hidup Pengembangan Sistem) dalam memperdalam metode pengumpulan data. Adanya penerapan SDLC dapat mengurai permasalahan, perubahan dan pengembangan yang dapat direalisasikan oleh unit usaha ini. Penerapan sistem informasi pada Kantin Ilmu menggunakan perangkat lunak sederhana dalam penginputan data. Namun, dengan melakukan perubahan mekanisme transaksi konvensional menuju era masa kini, membutuhkan adanya komitmen dan integritas manajemen agar dapat menciptakan iklim usaha yang kondusif. Sehingga, peran serta Kantin Ilmu dalam meningkatkan kesejahteraan bagi pegiat usaha skala kecil dan menengah di wilayah pantura dapat teralisasikan secara transparansi. Melalui sistem yang diusulkan, stakeholder dapat mengetahui keuntungan dan kerugian secara periodik. Dengan demikian akan membantu entitas pemilik unit usaha dalam menetapkan strategi yang digunakan untuk mencapai visi dan misi.

Kata Kunci: Sistem Informasi Manajemen; SDLC; UMKM; Pengembangan Kantin.

\section{PENDAHULUAN}

Perkembangan Usaha Mikro, Kecil, dan Menengah (UMKM) di Indonesia cukup menjanjikan. UMKM dinilai sebagai pemegang peranan yang sangat penting dan menjadi basis pembangunan ekonomi kerakyatan. Hadirnya UMKM juga sebagai salah satu solusi dalam sistem perekonomian yang dapat menyerap tenaga kerja sebanyak-banyaknya dan bersaing dengan perusahaan yang lebih menggunakan modal besar (Capital Intensive). Di balik eksistensi UMKM dalam menjalankan usaha terdapat beberapa kendala yang dihadapi dalam Lahamid (2018) diantaranya pengetahuan sumber daya manusia yang rendah, minimnya pengembangan teknologi informasi dan kesulitan memperoleh pembiayaan perbankan karena syarat-syarat yang belum terpenuhi. ${ }^{1}$ Solusi pemerintah sebagai stakeholder pemegang kebijakan untuk para pelaku UMKM memberikan sumbangsih berupa peminjaman modal (Setiaji, 2019). ${ }^{2}$ Bantuan bagi pelaku usaha memang dibutuhkan untuk menunjang usaha dalam menghadapi gempuran produk global.

Permasalahan yang lain yang dihadapi oleh UMKM adanya liberalisasi perdagangan dengan pemberlakuan ASEAN-China Free Trade Area (ACFTA) yang berlaku sejak 2010.3 Dimana kesepakatan yang telah dilakukan oleh

\footnotetext{
${ }^{1}$ Qomariah Lahamid. Nurlasera. "Hambatan dan Upaya Usaha Mikro Kecil Menengah (Umkm) Kreatif Berbasis Syariah di Kota Pekanbaru.” Sosial Budaya, Vol.15, No. 1, 2018, 27-36.

2 Rifki Danang Setiaji. "Petunjuk Teknis Bantuan Pemerintah bagi Wirausaha Pemula 2019. Diakses pada http://pembiayaan.depkop.go.id/index.php/public/regulasi pada oleh Kementerian Koperasi dan UKM Deputi Bidang Pembiayaan pada 18 Mar 2019 1-33.

3 Ragimun Sudaryanto. Wijayanti, R.R. "Strategi Pemberdayaan UMKM menghadapi Pasar Bebas Asean”. Jakarta: Jurnal Pusat Kebijakan Ekonomi Makro, Badan Kebijakan Fiskal Kementerian Keuangan, 2013, 1-32.
} 
pemerintah tidak melihat adanya kesiapan UMKM dalam memperbaiki kualitas produk, persaingan harga, serta peta positioning pasar yang belum memadai.

Berdasarkan Global Human Capital Index dalam World Economic Forum (2017), Indonesia menempati peringkat 65 dari 130 negara. 4 Sedangkan, daya saing Indonesia dalam survei International Institute for Management Development atau IMD (2017), berada di peringkat 42 dari 63 negara.5 Peringkat daya saing tersebut masih dibawah negara-negara kawasan ASEAN, seperti Singapura yang berada pada peringkat ke-3, Malaysia (24), Thailand (27), serta Filipina berada pada peringkat ke-41.

Peringkat tersebut harus seimbang bagi Indonesia dalam menghadapi persaingan aliran bebas barang/jasa, investasi dan/atau tenaga kerja bagi negara-negara ASEAN baik melalui kesepakatan ACFTA pada 2010 dan perjanjian MEA pada 2015. Hal ini menjadi kesempatan dalam menerima tantangan atau peluang bagi Indonesia demi meningkatkan stabilitas perekonomian di kawasan ASEAN. Sebagai provinsi dengan jumlah UMKM terbanyak ke-2 pada Sensus Ekonomi yang dilakukan Badan Pusat Statistik pada tahun 2019, Jawa Timur memegang peranan penting menjadi basis pembangunan ekonomi kerakyatan. Pemerintah Jawa Timur melihat besaran jumlah koperasi dan UMKM ini sebagai peluang untuk memperkuat perekonomian dengan berbasis pada ekonomi kerakyatan. Dinas Koperasi dan UMKM Provinsi Jawa Timur di tahun 2015 menargetkan adanya indikator kinerja pada keaktifan Koperasi, Rasio PDRB UMKM terhadap Total PDRB, pertumbuhan wirausahawan baru dan adanya perputaran modal Koperasi Wanita. 6

Pertumbuhan kuantitas UMKM provinsi Jawa Timur mengalami fluktuasi peringkat dari data yang diberikan. Daerah perkotaan cenderung memiliki jumlah UMKM yang lebih sedikit dibandingkan wilayah lainnya yang berada di provinsi Jawa Timur. Daerah industri seperti kabupaten Gresik memiliki peringkat lebih rendah dari pada kabupaten Trenggalek yang mengalami pertumbuhan sebesar $71,91 \%$. Melihat fenomena tersebut, pada umumnya dalam setiap perjalanan usaha terdapat beberapa permasalahan Sumber Daya Manusia di Indonesia yang dapat menjadi perhatian pemerintah, diantaranya:7

1. Output pendidikan formal yang belum siap kerja;

2. Missmatch antara dunia pendidikan/pelatihan kerja dengan industri;

3. Kualitas tenaga kerja yang mencerminkan tingkat pendidikan rendah;

4. Status pekerjaan utama didominasi pekerja informal;

\footnotetext{
4 World Economic Forum. "The Global Human Capital Report 2017 Preparing People for The Future of Work" dalam https://doi.org/ISBN 978-1944835-10-1, pada 2017, 9-21.

5 IMD. "IMD World Digital Competitiveness Ranking 2017" dalam https://doi.org/10.1080/0144287042000208233 pada 2017, 14-21

6 Dinas Koperasi dan UMKM Provinsi Jawa Timur. Rencana Strategis: Pemberdayan Koperasi dan Usaha Mikro, Kecil, dan Menengah (KUMKM) Provinsi Jawa Timur Tahun 2014-2019. Lihat http://diskopukm.jatimprov.go.id/info/renstra pada 2015.

7 Erisva Hakiki Purwaningsih, Dkk. "Rencana Pengembangan SDM TIK di Indonesia melalui Sertifikasi SKKNI Bidang KOMINFO.” (Jakarta: Puslitbang SDPPI, Kementerian Komunikasi dan Informatika, 2018), 61.
} 
5. Produktivitas tenaga kerja relatif rendah;

6. Industri belum melakukan penerimaan karyawan sesuai dengan kompetensi.

Tabel 1.

Perkembangan UMKM Provinsi Jawa Timur

\begin{tabular}{|c|c|c|c|c|c|c|}
\hline KABUPATEN/ KOTA & $\begin{array}{l}\text { UMKM } \\
2012\end{array}$ & \multirow{2}{*}{$\begin{array}{l}\text { Rank } \\
2012\end{array}$} & KABUPATEN/KOTA & $\begin{array}{l}\text { UMKM } \\
2018\end{array}$ & \multirow{2}{*}{$\begin{array}{r}\text { Rank } \\
2018\end{array}$} & $\%$ Growth \\
\hline $\begin{array}{c}\text { TOTAL UMKM JAWA } \\
\text { TIMUR } 2012 \\
\end{array}$ & 6.825 .931 & & $\begin{array}{c}\text { TOTAL UMKM } \\
\text { JAWA TIMUR } 2018 \\
\end{array}$ & 9.782 .262 & & $43 \%$ \\
\hline (1) & (2) & (3) & (4) & (5) & (6) & (7) \\
\hline BANGKALAN & 166.768 & 25 & BANGKALAN & 248.664 & 20 & $49,11 \%$ \\
\hline BANYUWANGI & 296.706 & 3 & BANYUWANGI & 480.687 & 3 & $62,01 \%$ \\
\hline BLITAR & 255.622 & 7 & BLITAR & 373.447 & 8 & $46,09 \%$ \\
\hline BOJONEGORO & 281.967 & 4 & BOJONEGORO & 376.316 & 7 & $33,46 \%$ \\
\hline BONDOWOSO & 172.378 & 22 & BONDOWOSO & 271.793 & 18 & $57,67 \%$ \\
\hline GRESIK & 168.393 & 24 & GRESIK & 225.242 & 25 & $33,76 \%$ \\
\hline JEMBER & 424.151 & 1 & JEMBER & 647.416 & 1 & $52,64 \%$ \\
\hline JOMBANG & 188.614 & 18 & JOMBANG & 299.273 & 13 & $58,67 \%$ \\
\hline KEDIRI & 251.493 & 9 & KEDIRI & 380.056 & 6 & $51,12 \%$ \\
\hline KOTA BATU & 23.544 & 35 & KOTA BATU & 44.963 & 33 & $90,97 \%$ \\
\hline KOTA BLITAR & 21.291 & 37 & KOTA BLITAR & 29.123 & 37 & $36,79 \%$ \\
\hline KOTA KEDIRI & 29.306 & 32 & KOTA KEDIRI & 45.629 & 32 & $55,70 \%$ \\
\hline KOTA MADIUN & 22.662 & 36 & KOTA MADIUN & 36.555 & 35 & $61,31 \%$ \\
\hline KOTA MALANG & 77.778 & 31 & KOTA MALANG & 117.840 & 31 & $51,51 \%$ \\
\hline KOTA MOJOKERTO & 17.480 & 38 & KOTA MOJOKERTO & 18.995 & 38 & $8,67 \%$ \\
\hline KOTA PASURUAN & 24.257 & 34 & KOTA PASURUAN & 35.596 & 36 & $46,75 \%$ \\
\hline KOTA PROBOLINGGO & 26.125 & 33 & KOTA PROBOLINGGO & 43.478 & 34 & $66,42 \%$ \\
\hline KOTA SURABAYA & 260.762 & 6 & KOTA SURABAYA & 385.054 & 5 & $47,66 \%$ \\
\hline LAMONGAN & 252.734 & 8 & LAMONGAN & 312.376 & 12 & $23,60 \%$ \\
\hline LUMAJANG & 196.446 & 15 & LUMAJANG & 287.778 & 16 & $46,49 \%$ \\
\hline MADIUN & 146.562 & 29 & MADIUN & 191.880 & 29 & $30,92 \%$ \\
\hline MAGETAN & 154.800 & 28 & MAGETAN & 181.760 & 30 & $17,42 \%$ \\
\hline MALANG & 414.516 & 2 & MALANG & 600.054 & 2 & $44,76 \%$ \\
\hline MOJOKERTO & 155.410 & 27 & MOJOKERTO & 216.518 & 27 & $39,32 \%$ \\
\hline NGANJUK & 201.463 & 14 & NGANJUK & 288.119 & 15 & $43,01 \%$ \\
\hline NGAWI & 185.312 & 19 & NGAWI & 253.870 & 19 & $37,00 \%$ \\
\hline PACITAN & 181.115 & 21 & PACITAN & 212.197 & 28 & $17,16 \%$ \\
\hline PAMEKASAN & 195.554 & 16 & PAMEKASAN & 247.269 & 22 & $26,45 \%$ \\
\hline PASURUAN & 248.802 & 10 & PASURUAN & 362.230 & 9 & $45,59 \%$ \\
\hline PONOROGO & 207.561 & 13 & PONOROGO & 283.967 & 17 & $36,81 \%$ \\
\hline PROBOLINGGO & 235.286 & 11 & PROBOLINGGO & 333.453 & 10 & $41,72 \%$ \\
\hline SAMPANG & 195.215 & 17 & SAMPANG & 229.644 & 24 & $17,64 \%$ \\
\hline SIDOARJO & 171.264 & 23 & SIDOARJO & 248.306 & 21 & $44,98 \%$ \\
\hline SITUBONDO & 156.727 & 26 & SITUBONDO & 217.042 & 26 & $38,48 \%$ \\
\hline SUMENEP & 269.005 & 5 & SUMENEP & 401.210 & 4 & $49,15 \%$ \\
\hline TRENGGALEK & 143.455 & 30 & TRENGGALEK & 246.614 & 23 & $71,91 \%$ \\
\hline TUBAN & 223.998 & 12 & TUBAN & 319.477 & 11 & $42,62 \%$ \\
\hline TULUNGAGUNG & 181.409 & 20 & TULUNGAGUNG & 288.371 & 14 & $58,96 \%$ \\
\hline
\end{tabular}

Sumber: Dinas Koperasi dan UMKM Provinsi Jawa Timur. Data UKM

http://diskopukm.jatimprov.go.id/info/data-ukm2019 pada 2019, data diolah. 
Permasalahan yang dominan dari suatu kelompok bisnis bila dikaji lebih lanjut dari pernyataan diatas yakni berkaitan dengan kemampuan manajerial seperti pengelolaan administrasi (keuangan dan operasional), keterbatasan pengetahuan yang dimiliki pemilik usaha, sistem informasi usaha yang belum terstruktural. Namun sebagai pemula cenderung belum dapat memisahkan antara pemasukan dan pengeluaran keuangan pada usaha yang baru dirintis.

Semakin berkembangnya teknologi informasi yang telah digunakan oleh perusahaan-perusahaan besar, dapat dijadikan sebagai sarana untuk membantu kelancaran proses bisnis untuk mencapai keuntungan maksimal. Pemanfaatan teknologi informasi juga dapat mencatat pembukuan pada buku besar dan beralih pada data komputerisasi yang tersismem dengan baik. Sehingga karyawan dalam perusahaan dapat bekerja secara cepat, efisien dan efektif dalam memenuhi target yang akan dicapai.

Perusahaan yang menciptakan iklim kerja melalui sistem informasi manajemen dapat didefinisikan sebagai serangkaian komponen yang berhubungan dalam mengumpulkan, memproses, menyimpan, dan mendistribusikan informasi yang mendukung pengambilan keputusan dan pengawasan di dalam sebuah organisasi. ${ }^{8}$ Pendapat lain mengatakan sistem informasi merupakan suatu sistem di dalam suatu organisasi yang mempertemukan kebutuhan pengolahan transaksi harian yang mendukung fungsi operasi organisasi yang bersifat manajerial dengan kegiatan strategi dari suatu organisasi untuk dapat menyediakan kepada pihak luar tertentu dengan laporan-laporan yang diperlukan. ${ }^{9}$

Menurut Terry (2004) fungsi manajemen terdiri dari, (1) Planning, yaitu proses penentuan tujuan, strategi, dan kebijakan yang dibutuhkan untuk mencapai tujuan, (2) Organizing, yaitu proses pembagian tugas, wewenang, dan sumber daya di antara anggota organisasi untuk mencapai tujuan tertentu, (3) Actuating, yaitu proses memotivasi, membimbing, dan mengarahkan karyawan dalam rangka mencapai tujuan, (4) Controlling, yaitu fungsi manajemen yang berhubungan dengan prosedur pengukuran hasil kinerja terhadap tujuan perusahaan. ${ }^{10}$

Selain itu, pengelolaan yang baik juga dilihat dari beberapa faktor yang diidentifikasi dalam lingkungan internal perusahaan, (1) Sumber Daya Manusia, yaitu suatu proses untuk memperoleh, melatih, menilai, dan memberikan kompensasi kepada karyawan, serta memperhatikan hubungan kerja dengan karyawan, (2) Keuangan, yaitu keputusan investasi dan keputusan pembiayaan, (3) Produksi dan Operasi, yaitu semua aktivitas yang mengubah input menjadi barang dan jasa, (4) Pemasaran, yaitu proses pendefinisian, pengantisipasian, penciptaan, serta pemenuhan kebutuhan dan keinginan konsumenakan produk dan jasa. ${ }^{11}$

\footnotetext{
8 Kenneth C. Laudon \& Jane P. Laudon, Management Information Systems: Managing The Digital Firm, Twelfth Edition (New Jersey: Prentice Hall Inc., 2012), 47.

9 Tata, Sutabri. Analisis Sistem Informasi (Yogyakarta: CV. Andi Offset, 2012).38.

${ }^{10}$ Terry, G. R . Prinsip-prinsip Manajemen, Jakarta: PT. Bumi Aksara, 2004, 4.

${ }^{11}$ Fred R. David, Manajemen Strategi. Edisi Kesepulu Jilid 1 (Jakarta: Salemba Empat, 2009), 7.
} 
Fokus penelitian ini adalah model operasional Badan Usaha Milik Kampus yang dijalankan sebagai sarana kegiatan praktik mahasiswa STEI Kanjeng Sepuh. "Kantin Ilmu” merupakan kegiatan praktik yang diprakarsai Perkumpulan Kanjeng Sepuh yang berlokasi di kecamatan Sidayu kabupaten Gresik. Kantin atau koperasi sekolah bagi setiap lembaga atau organisasi dapat dijadikan sebagai salah satu usaha dan upaya untuk meningkatkan perekonomian suatu lembaga. Manfaat yang dapat diambil dari kegiatan praktik ini sebagai sarana pelatihan kepada mahasiswa guna mengelola kegiatan kantin baik operasional, keuangan dan manajerial.

Kantin memiliki makna sebagai salah satu sarana dari lembaga atau organisasi yang digunakan sebagai tempat pembelian makanan dan minuman. Kantin sekolah adalah tempat dimana warga sekolah membeli makanan jajan, baik berupa pangan siap saji maupun pangan olahan. ${ }^{12}$ Lebih lanjut kantin sekolah merupakan salah satu tempat jajan anak atau mahasiswa, selain penjaja makanan jajanan di luar sekolah. ${ }^{13}$ Kantin juga memiliki peranan penting bagi pembeli dalam mewujudkan pesan-pesan kesehatan dan menentukan perilaku konsumsi sehari-hari melalui penyediaan makanan jajanan di sekolah. ${ }^{14}$

Dalam mempertahankan usahanya, kantin sekolah juga melihat lingkungan eksternal yang diperlukan untuk mengetahui faktor-faktor yang dapat memberikan peluang dan ancaman bagi lingkungan usaha. Lingkungan eksternal terdapat 5 (lima) jenis yang terdiri dari ancaman pendatang baru, kekuatan tawar-menawar pemasok, kekuatan tawar-menawar pembeli, ancaman produk substitusi, persaingan diantara para anggota industri. ${ }^{15}$ Kantin ini beroperasi dengan mendatangkan pemasok dari luar untuk dapat bergerak efisien melalui pengambil prosentase laba. Aturan yang mengikat terkait kebersihan, kualitas dan kehalalan produk yang dijual menjadi upaya utama kantin dalam melayani konsumen.

Berdasarkan latar belakang yang telah dipaparkan dengan mengacu adanya tantangan UMKM kabupaten Gresik, penulis mengajukan rumusan masalah sebagai berikut :

1. Bagaimana penerapan sistem informasi manajemen pada kantin ilmu?

2. Bagaimana perkembangan manajemen kantin ilmu sebelum dan setelah adanya penerapan sistem informasi manajemen?

3. Bagaimana upaya mempertahankan perkembangan sistem informasi manajemen pada kantin ilmu?

\section{METODE PENELITIAN}

Metode penelitian dalam artikel ini bersifat deskriptif dengan pendekatan kualitatif, di mana peneliti mendeskripsikan dan menganalisis

\footnotetext{
12 Nababan Halim, Keamanan Pangan di Kantin Sekola (Jakarta: Direktorat Survei dan Penyuluhan Keamanan Pangan Deputi Bidang Pengawasan Keamanan Pangan dan Bahan Berbahaya BPOM RI, 2012),8-21.

${ }^{13}$ Lilis Nuraida, Dkk. Menuju Kantin Sehat di Sekolah (Jakarta: Direktorat Jenderal Pendidikan Dasar Kementerian Pendidikan Nasional, 2011), 10.

14 Ibid., 8.

15 Michael. E. Porter, Strategi Bersaing: Teknik Menganalisis Industri dan Pesaing. Terjemahan Agus Maulana (Jakarta: Erlangga, 1997), 234.
} 
fenomena, peristiwa, sikap, dan persepsi secara individual maupun kelompok guna menemukan prinsip-prinsip dan penjelasan yang mengarah pada kesimpulan. ${ }^{16}$

Penelitian ini termasuk pada penelitian lapangan yang mendapatkan sejumlah informasi secara langsung dimana sumber data utama (primer) dari pihak pengelola kantin ilmu Kanjeng Sepuh Sidayu Gresik. Pengambilan sumber data sekunder diperoleh melalui literasi (buku, jurnal, atau artikel) yang relevan dengan topik penelitian.

Dalam memperoleh data dalam penelitian ini, penulis menggunakan metode pengumpulan data berupa wawancara semi terstruktur yaitu interview dengan membuat garis besar pokok-pokok pembicaraan, namun dalam pelaksanaannya interviewer mengajukan pertanyaan secara bebas. ${ }^{17}$ Informasi yang telah diperoleh dari sumber utama dan sekunder diolah dengan urutan (a) Menelaah seluruh data dari berbagai sumber, (b) Melakukan reduksi data, (c) Kategorisasi, dan (d) Penafsiran data. ${ }^{18}$ Untuk pengujian keabsahan data, peneliti menggunakan metode pengujian data berupa trianggulasi sumber dengan membandingkan dan melakukan pengecekan derajat kepercayaan suatu informasi yang diperoleh dari berbagai sumber dalam pada lingkungan internal maupun eksternal usaha.

\section{Analisa Sistem}

Dalam memperdalam metode pengumpulan data pada sistem objek penelitian yang telah diberikan, peneliti menggunakan SDLC (System Development Life Cycle atau Siklus Hidup Pengembangan Sistem). SDLC merupakan proses pembuatan dan perubahan sistem serta model dan metodologi yang dikembangkan pada sistem yang telah berlangsung. Tahapan yang dapat dilalui dalam menerapkan SDLC, yaitu: 19

1. Perencanaan Sistem; merupakan tahapan dimana sistem digambarkan secara global beserta tujuan terhadap sistem yang akan dikembangkan

2. Analisa Sistem; merupakan penguraian masalah sistem ke dalam sebuah diagram atas situasi yang sedang berjalan serta pemberian desain solusi atas masalah yang terjadi.

3. Desain Sistem; merupakan solusi yang telah digambarkan pada tahap analisa diuraikan secara detail dalam bentuk diagram, layouts, business rules, dan dokumentasi lain yang dibutuhkan.

4. Implementasi Sistem; merupakan tahapan uji coba (testing) sistem atas desain yang telah diberikan.

5. Perawatan Sistem; merupakan tahapan perbaikan dan pengembangan atas sistem yang telah berjalan.

16 Nana Syaodih Sukmadinata, Metode Penelitian Pendidikan ( Bandung : PT Remaja Rosdakarya, 2011). 60.

17 Djam'an Satori \& Aan Komariah, Metodologi Penelitian Kualitatif (Bandung: Alfabeta CV, 2011), 49.

${ }^{18}$ Lexy. J. Moleong , Metode Penelitian Kualitatif (Bandung: PT Remaja Rosdakarya Cet. XXVI, 2009), 247.

19 Sri Mulyani, Metode Analisis dan Perancangan Sistem (Bandung : Abdi Sistematika, 2016), 24. 


\section{HASIL PENELITIAN DAN PEMBAHASAN}

\section{Gambaran Umum Kantin Ilmu Kanjeng Sepuh Gresik}

Kantin ilmu merupakan sarana pembelajaran bagi mahasiswa STEI Kanjeng Sepuh Gresik dalam mengasah kemampuan manajerial usaha retail dan penerapan keilmuan lainya. Upaya ini dibentuk dengan harapan agar mahasiswa mampu mengasah keahlian dan persiapan menuju kemandirian setelah lulus dari perkuliahan. Kantin ilmu berdiri sejak tahun 2019 silam yang merupakan hasil penggabungan operasional manajemen kantin yang berada pada masing-masing unit pendidikan yang berada dibawah naungan Perkumpulan Kanjeng Sepuh. Proses penggabungan kantin-kantin ini ditujukan sebagai sarana pengembangan keahlian mahasiswa STEI Kanjeng Sepuh agar tercapai visi dan misi kampus. Perubahan operasional manajemen kantin juga diperuntukan agar manajemen kantin memiliki pelaporan keuangan yang seragam dengan memberikan edukasi kepada pembeli untuk melakukan transaksi secara jujur dan berprinsip syariah. Sistem pengelolaan Kantin Ilmu memiliki struktur organisasi dalam kelancaran usaha, diantaranya

Gambar 1.

Struktur Organisasi Kantin Ilmu Kanjeng Sepuh

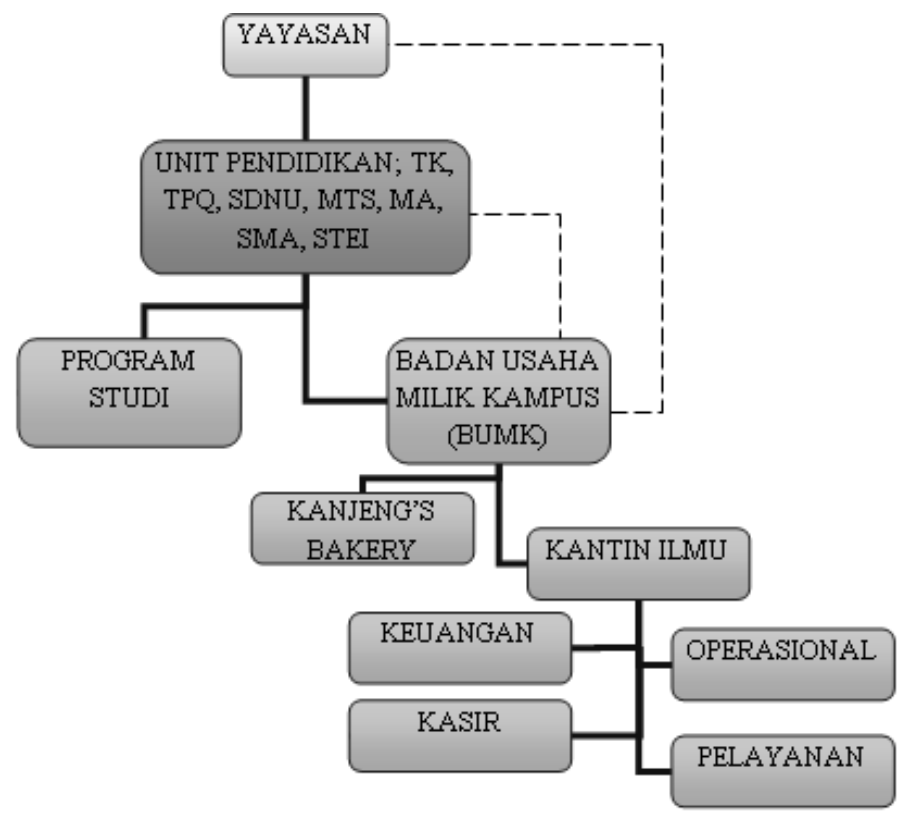

Peralihan operasional kantin ilmu dipimpin oleh ketua yang ditunjuk dari Badan Usaha Milik Kampus (BUMK) STEI Kanjeng Sepuh Sidayu Gresik. Adapun konsep kantin bagi pelanggan yang melakukan transaksi berupa kantin kejujuran dan pojok baca. Pelanggan yang menjadi objek transaksi adalah pelajar dari tingkat SD, SMP, SMA/MA, Perguruan Tinggi dan sebagainya. Barang yang diperdagangkan seputar makanan ringan maupun olahan dari suplier kantin dan hasil produksi mahasiswa STEI Kanjeng Sepuh. 


\section{Penerapan dan Perkembangan Sistem Informasi pada Kantin Ilmu}

Sistem operasional kantin sekolah yang berada di linkungan yayasan mengalami beberapa kendala pada saat tahap implementasi. Berdasarkan dari informasi dari pengelola, didapati bahwa kendala utama terletak pada proses transaksi secara desentralisasi pengelelolaan yang tidak adanya pelaporan pemasukan kepada yayasan.

Kantin ilmu telah menerapkan proses pelaporan transaksi dengan menggunakan software Microsoft Excel. Upaya penggunaan software ini digunakan pada pengelola kantin imu bertujuan untuk mengetahui pelaporan keuangan seperti laba-rugi, stok barang dan aset kepemilikan yang dimiliki. Sebelum mengenal adanya pelaporan berbasis teknologi informasi, pengelola kantin mengalami kendala untuk mengetahui porsi keuntungan dan kerugian yang diperoleh dalam kurun waktu harian, mingguan, dan bulanan.

Setelah mengenal adanya sistem informasi, pengelolaan kantin menjadi teratur dan tertib administrasi. Setelah diterapkannya sistem informasi berupa penggunaan software Microsoft Excel dalam penginputan data, manajer BUMK dapat mengetahui laporan keuangan baik dalam posisi laba/rugi dalam skala periode waktu yang akan dilaporkan. Dengan diberlakukannya sistem informasi ini, manajer dapat menentukan dan membandingkan prosentase keuntungan atau kerugian yang diperoleh dari laporan keuangan. Kemudahan ini dirasakan oleh manajer untuk menentukan strategi-strategi lanjutan dalam pencapaian target kantin.

Khusnia selaku pengawas kantin ilmu merasakan adanya manfaat yang diperoleh dimana tata kelola keuangan menjadi baik dan teratur. Pengelola harus memiliki komitmen dalam mempertahankan manfaat yang sudah diterima sesuai dengan Standar Operasional Prosedur (SOP) yang berlaku bagi setiap lini usaha. ${ }^{20}$

\section{Upaya Mempertahankan Perkembangan Sistem Informasi Manajemen pada Kantin Ilmu}

Keberhasilan manajer dalam menerapkan sistem informasi dapat memiliki hambatan dimana pengelola kantin harus menyatukan persepsi, memahami karakter pegawai hingga cara berfikir dari tiap pengelola kantin. Setelah manajer memahami karakter masing-masing pegawainya, manajer memberikan job deskripsi kepada pegawai sesuai dengan kemampuan dan karakter masing-masing dalam mewujudkan visi dan misi kantin ilmu kanjeng sepuh.

Adanya pembagian job deskripsi kepada pengelola, dijumpai masih terdapat kendala-kendala yang dijumpai. Dalam mengatasi kendala-kendala yang ada, pengelola melakukan pertemuan rapat dalam jangka waktu mingguan dan bulanan. Dalam proses rapat yang sedang berlangsung dapat dijadikan sebagai bahan evaluasi terkait perolehan dan hambatan yang dijumpai dalam menjalankan aktivitas kantin. Adanya pertemuan rapat dapat meningkatkan

${ }^{20}$ Indah Puji, Buku Praktis Mengembangkan SDM, (Jogjakarta: Laksana, 2014), 35. el-Qisț: Journal of Islamic Economics and Business (JIEB) 
motivasi dan membangun keeratan diantara karyawan dalam segala aspek kegiatan. ${ }^{21}$

Adapun peneliti melakukan analisis dalam upaya manajemen dalam menata ulang sistem administrasi berbasis teknologi memiliki tahapan-tahapan sebagai berikut:

\section{Analisa Dokumen}

$\begin{array}{lll}\text { a. } & \text { Nama } & \text { : Nota Penjualan } \\ \text { Dokumen } & \\ \text { Fungsi } & \text { : Catatan pemesanan konsumen } \\ \text { Sumber } & \text { : Kasir } \\ \text { Frekuensi } & \text { : Setiap Hari } \\ \text { Distribusi } & \text { : konsumen dan manajemen kantin } \\ \text { Isi Dokumen } & \text { : tanggal, nama menu, harga, jumlah \& total } \\ \text { b. Nama } & \text { : Daftar Menu } \\ \text { Dokumen } & \\ \text { Fungsi } & \text { : Daftar Menu dan Harga } \\ \text { Sumber } & \text { : Kasir } \\ \text { Frekuensi } & \text { : Setiap Hari } \\ \text { Distribusi } & \text { : konsumen } \\ \text { Isi Dokumen } & \text { : nama menu, harga, kategori menu } \\ \text { Nama } & \text { : Laporan Penjualan } \\ \text { Dokumen } & \text { : Rekap data Penjualan harian } \\ \text { Fungsi } & \text { : Pemilik } \\ \text { Sumber } & \text { : Setiap Hari } \\ \text { Frekuensi } & \text { :- } \\ \text { Distribusi } & \text { : tanggal laporan, nama menu, jumlah, subtotal, total } \\ \text { Isi Dokumen } & \text { penjualan }\end{array}$

\section{Analisa Sistem yang Berjalan}

Sistem yang berjalan merupakan rantai proses transaksi di Kantin Ilmu Kanjeng Sepuh, di antaranya:

\section{Proses Skema Persediaan Barang}

Proses yang berjalan pada tahap persediaan (gudang) kepada supplier dapat digambarkan pada skema di bawah ini:

\footnotetext{
${ }^{21}$ Jiputra, Juan A. "Pengaruh Gaya Kepemimpinan Partisipatif, Kepuasan Kerja dan Motivasi Kerja, Terhadap Kinerja Karyawan pada Divisi Penjualan PT Rembaka" dalam Agora Vol. 7 No. $1,2019$. 
Gambar 2.

Flow Chart Persediaan (Gudang) berjalan

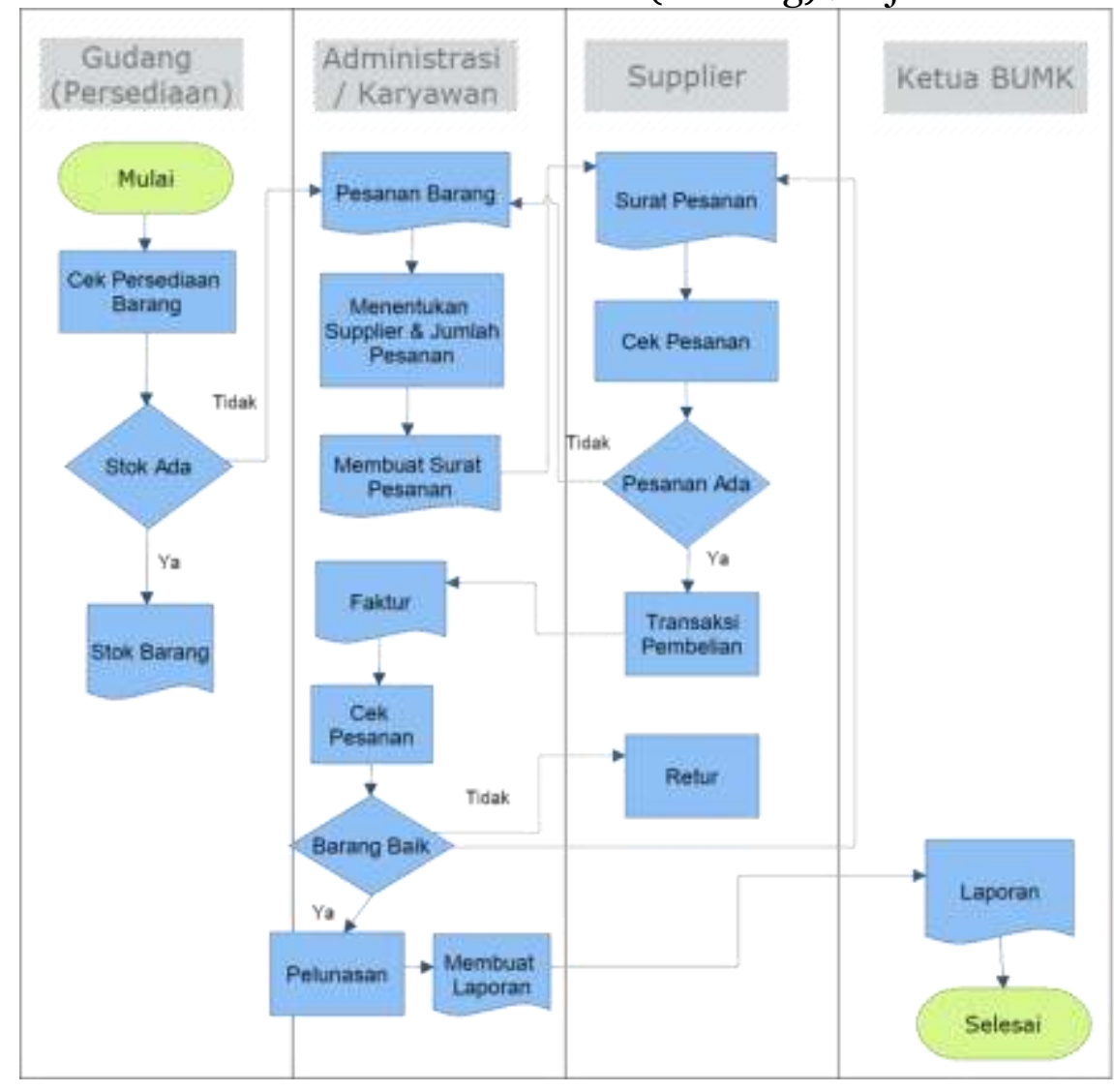

Berdasarkan bagan skema proses persediaan dari transaksi yang berjalan, berikut prosedur sistem yang dapat diusulkan.

1) Karyawan gudang melakukan pencatatan barang yang tersedia didalam gudang untuk dijual kembali kepada pelanggan. Persediaan (stok) yang tersedia dapat dimasukkan kepada transaksi penjualan berikutnya, sebaliknya apabilai persediaan barang tidak tersedia, karyawan melakukan pemesanan kepada suplier untuk melengkapi kebutuhan penjualan.

2) Karyawan administrasi mencatat barang yang tidak tersedia untuk dipesankan sesuai kebutuhan kantin. Karyawan administrasi memilih suplier atau agen penjualan yang dapat dipercaya, kualitas harga dan pengiriman barang yang tepat. Apabila terdapat suplier yang amanah diberikan akad kerjasama dengan pengelola kantin sebagai penyalur makanan dan penjualan. Karyawan administrasi membuat surat pemesanan (purchase order) kepada suplier sesuai kebutuhan kantin.

3) Supplier yang ditunjuk dan telah dihubungi oleh karyawan administrasi, melakukan pengecekan kembali terhadap jenis dan jumlah barang yang akan dibeli. Suplier melakukan pengecekan pemesanan barang, apabila tersedia, suplier melakukan pengiriman.

4) Barang yang telah dikirimkan harus melalui proses pengecekan kondisi secara fisik dan tanggal kadaluarsa. Apabila tidak ada kecacatan produk yang diterima, karyawan administrasi melakukan pelunasan pembayaran. 
5) Mutasi barang masuk/keluar dicatat secara berkala baik harian, mingguan, dan bulanan untuk dibuatkan laporan kepada ketua BUMK sebagai bahan evaluasi bulanan pada transaksi kantin di masing-masing unit pendidikan.

\section{Proses Skema Penjualan}

Proses yang berjalan pada tahap penjualan kepada pelanggan dapat digambarkan pada skema dibawah ini,

\section{Gambar 3 .}

Flow Chart Penjualan

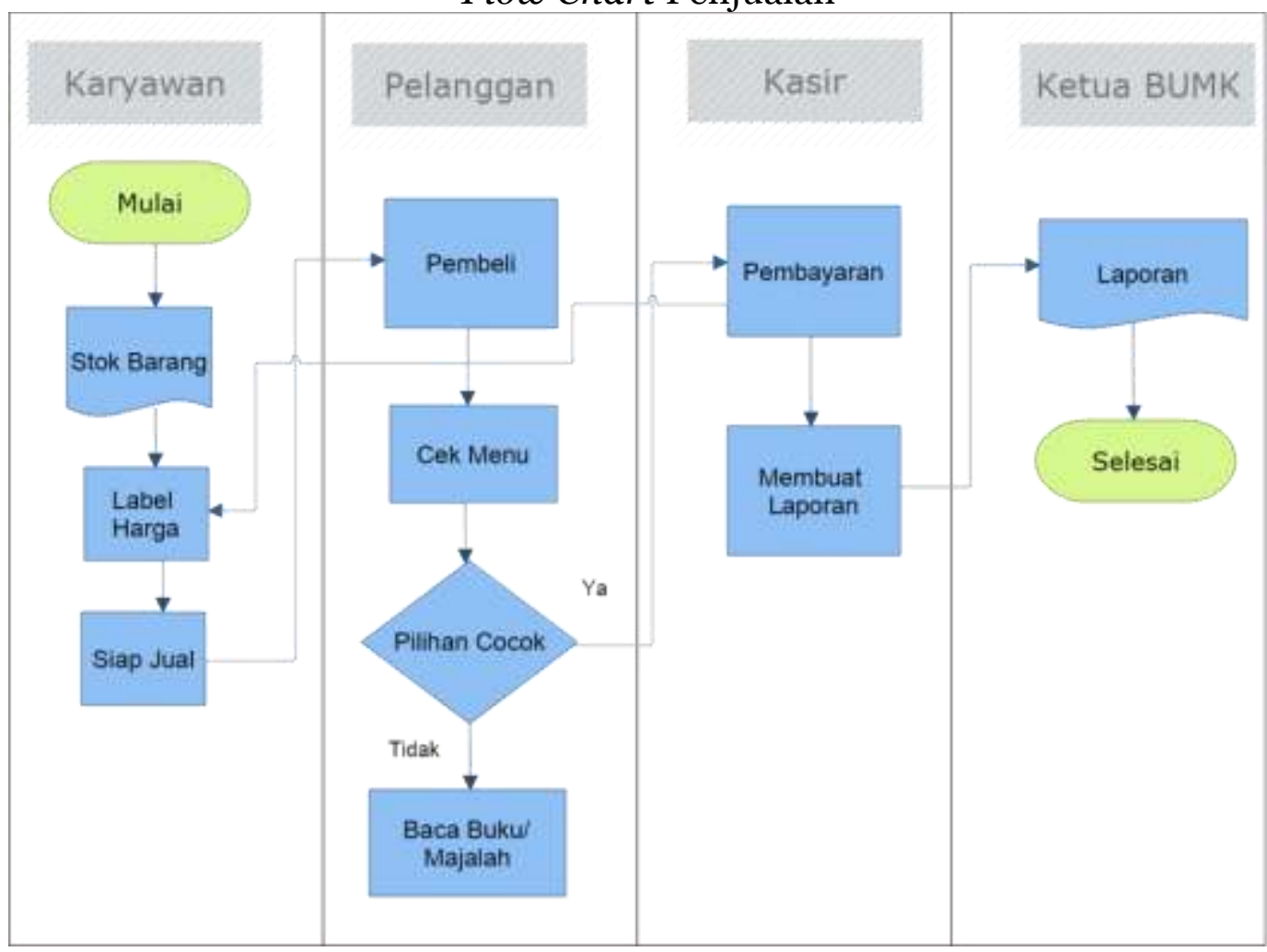

Berdasarkan bagan skema proses persediaan dari transaksi yang berjalan, berikut prosedur sistem yang dapat diusulkan:

1) Karyawan penjualan melakukan pencatatan barang yang tersedia didalam gudang untuk dijual kembali kepada pelanggan. Persediaan (stok) yang tersedia dapat diberikan label harga sesuai dengan ketentuan yang dibeli pelanggan. Apabila barang telah diberi label harga, maka barang siap untuk dijual kepada pelanggan.

2) Pembeli yang terdapat pada kantin masing-masing unit pendidikan melakukan pemilihan menu yang sesuai selera. Pembeli yang telah menentukan pilihan menu yang tepat dapat melakukan pembayaran di kasir secara jujur sesuai dengan harga yang diberikan. Sedangkan pembeli yang masih memilih atau sudah membayar dapat mengunjungi pojok baca/majalah yang telah disediakan.

3) Kasir mencatat transaksi penjualan secara berkala baik harian, mingguan, dan bulanan untuk dibuatkan laporan kepada ketua BUMK sebagai bahan evaluasi bulanan pada transaksi kantin di masing-masing unit pendidikan. 


\section{Evaluasi Sistem yang Berjalan}

Proses pembuatan laporan penjualan berjalan menghasilkan beberapa permasalahan dan evaluasi yang diberikan sebagai berikut,

Tabel 2.

Evaluasi Sistem yang Berjalan

\begin{tabular}{|c|c|c|c|}
\hline No & Permasalahan & Entitias & Solusi \\
\hline 1 & $\begin{array}{c}\text { Banyaknya jumlah } \\
\text { transaksi harian } \\
\text { membutuhkan } \\
\text { waktu yang lama } \\
\text { dalam pemberian } \\
\text { laporan }\end{array}$ & $\begin{array}{l}\text { Ketua } \\
\text { BUMK }\end{array}$ & $\begin{array}{c}\text { Setiap transaksi dilakukan dengan } 2 \\
\text { hal, menyimpan bukti transaksi } \\
\text { secara manual dan diletakkan pada } \\
\text { database sistem. }\end{array}$ \\
\hline 2 & $\begin{array}{l}\text { Menggunakan } \\
\text { sistem penjualan } \\
\text { kantin kejujuran } \\
\text { yang tidak dapat } \\
\text { diketahui jumlah } \\
\text { transaksi yang } \\
\text { berlangsung. }\end{array}$ & Operasional & $\begin{array}{l}\text { Penghitungan transaksi dilakukan } \\
\text { sesuai mutasi barang saat pembelian } \\
\text { dengan suplier dan konsumen } \\
\text { melalui pengawasan pengelola } \\
\text { kantin. }\end{array}$ \\
\hline
\end{tabular}

Konsep entitas yang terlibat pada transaksi yang berjalan adalah bagian suplier, pelanggan dan pemilik yang memunculkan sistem sebagai berikut:

Gambar 4.

Flow Chart Data Sistem Informasi Penjualan pada Entitas Kepemilikan Kantin Ilmu

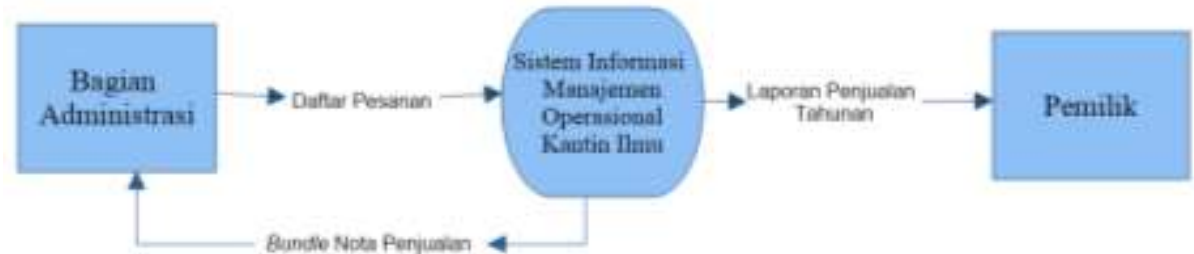

Sebagaimana bagan struktur organisasi yang dimiliki oleh kantin ilmu, pengendalian transaksi dipegang sepuhnya oleh tim pengelola dengan stakeholder yang dimiliki. Diagram diatas juga menunjukkan adanya laporan tahunan yang harus diberikan kepada pemilik seutuhnya yakni pengurus yayasan atau Perkumpulan Kanjeng Sepuh Sidayu Gresik. Dalam hal ini pengurus akan menerima prosentase penjualan sesuai dengan akad perjanjian penjualan setelah dikurangi biaya operasional kantin.

Dengan adanya perbaikan sistem informasi pada operasional kantin ilmu, ada banyak kesempatan peluang bagi para pegiat usaha dalam skala UKM yang dapat bergabung sebagai suplier. Besarnya peluang juga harus diseimbangi dengan adanya kesadaran manajemen untuk merubah sistem transaksi secara konvensional menuju transaksi di era masa kini. Dengan begitu, kantin melalui BUMK dapat bertransformasi menjadi suatu lembaga 
usaha benefit dengan mengembangkan produk dan pelayanan yang berkualitas agar memperoleh kepuasan konsumen.

Gambar 5 .

Flow Chart Desain Transaksi Kantin yang Diusulkan

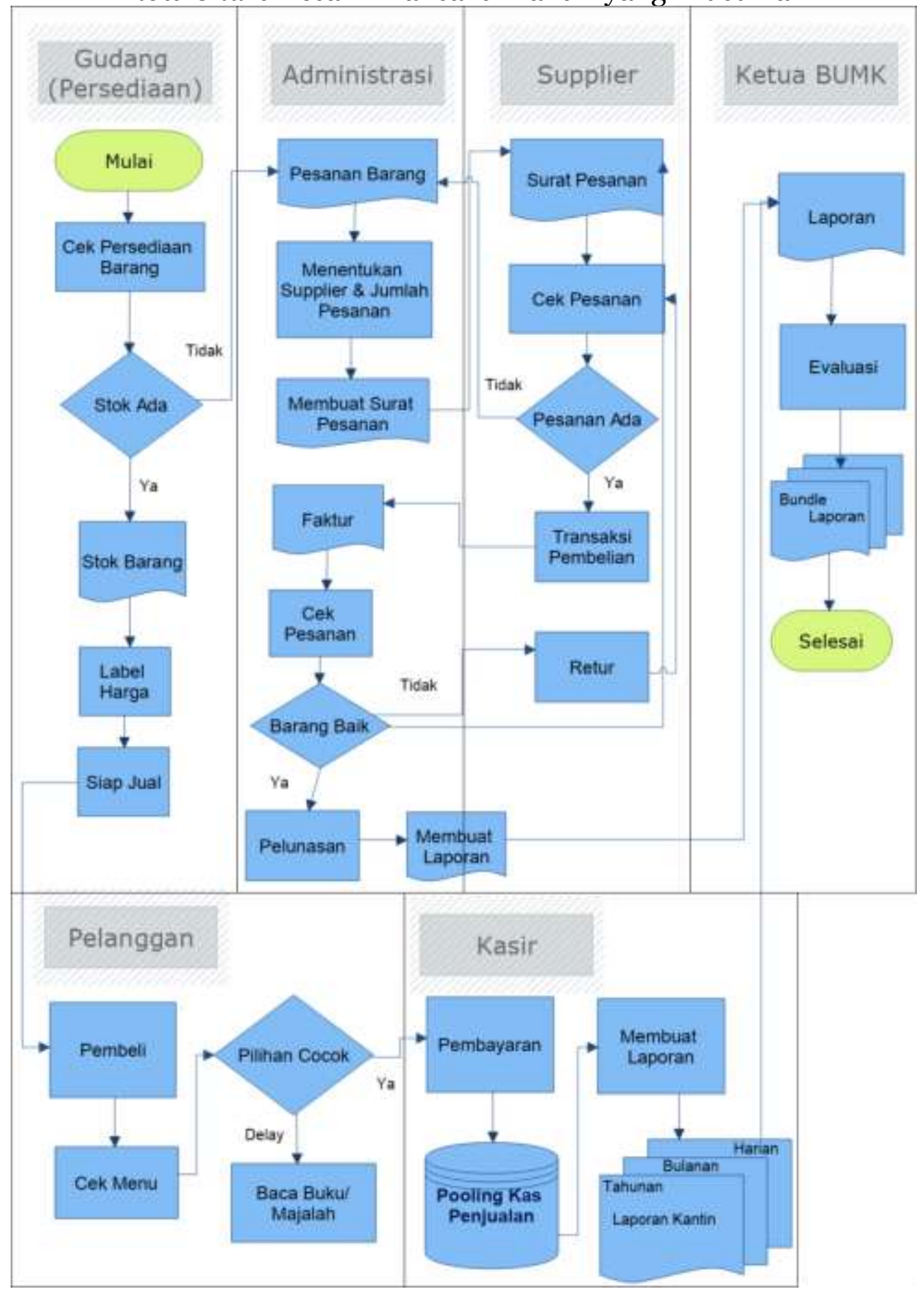

Berdasarkan bagan skema diatas setelah memperoleh permasalahan dalam proses transaksi kantin, berikut prosedur sistem yang dapat diusulkan setelah adanya peninjauan ulang: 
1) Kantin ilmu memiliki konsep kantin kejujuran dan pojok baca bagi setiap pelanggan yang ingin bertransaksi, namun terdapat beberapa kendala yang dijalani. Peneliti memberikan usulan perubahan sistem dengan memberikan tabulasi (polling) dana penjualan. Kantin dapat menambahkan 1 (satu) deskripsi pekerjaan pada karyawan operasional dengan memberikan beban tugas berupa cross-check jumlah barang yang sudah dijual dan berapa nominal yang telah diterima oleh kantin.

2) Pooling dana ini berikutnya dilaporkan secara berkala baik harian, mingguan dan bulanan agar dapat dilakukan sinkronisasi pelaporan keuangan pada bagian administrasi guna menghitung pembelian barang pada suplier. Laporan yang telah dibuat secara berkala dilaporkan kepada ketua BUMK untuk dijadikan sebagai bahan evaluasi dan rencana strategis tindak lanjut agar pelaksanaan kantin dapat berlangsung.

\section{KESIMPULAN}

Kesimpulan yang dapat diambil dari adanya penelitian, diantaranya: (1) data transaksi tersimpan dalam database sehingga mampu memudahkan pembeli dan penjual dalam proses tranksaksi yang sedang berlangsung. (2) laporan transaksi kantin berlaku secara periodik kepada BUMK dan Yayasan untuk dijadikan sebagai pedoman sistem informasi transaksi dengan menggunakan software Microsoft Excel. (3) Upaya mempertahankan perkembangan kantin melalui komitmen manajemen dengan mendayagunakan karyawan dan pegiat usaha di sektor UKM demi terwujudnya visi dan misi yang tepat sasaran.

\section{DAFTAR PUSTAKA}

Badan Pusat Statistika. Analisis Hasil SE2016 Lanjutan; Potensi Peningkatan Kinerja Usaha Mikro Kecil. Jakarta: Stastics Indonesia, 2019.

David, Fred R. Manajemen Strategi. Edisi Kesepuluh. Jilid 1. Jakarta: Salemba Empat, 2009.

Dinas Koperasi dan UMKM Provinsi Jawa Timur. Data UKM. Dikutip dari http://diskopukm.jatimprov.go.id/info/data-ukm2019 pada 2019.

. Rencana Strategis: Pemberdayan Koperasi dan Usaha Mikro, Kecil, dan Menengah (KUMKM) Provinsi Jawa Timur Tahun 2014-2019. Dikutip dari http://diskopukm.jatimprov.go.id/info/renstra pada 2015.

Fionita,I., Magdalena, B. "Penerapan Sistem Informasi Manajemen Pada Usaha Kecil Menengah Di Provinsi Lampung.” Jurnal Bisnis Darmajaya Vol. 01. No. 02, 2015.

Hadi, S. Metodologi Research: Jilid 2. Yogyakarta: Andi Offset, 1989.

IMD. "IMD World Digital Competitiveness Ranking 2017". Retrieved from https://doi.org/10.1080/0144287042000208233 pada 2017

Jiputra, Juan A. "Pengaruh Gaya Kepemimpinan Partisipatif, Kepuasan Kerja dan Motivasi Kerja, Terhadap Kinerja Karyawan pada Divisi Penjualan PT Rembaka”. Universitas Kristen Petra: Agora Vol. 7 No. 1, 2019.

Lahamid, Qomariah. Nurlasera. Hambatan dan Upaya Usaha Mikro Kecil Menengah (Umkm) Kreatif Berbasis Syariah di Kota Pekanbaru. Sosial Budaya, Vol.15, No. 1, 2018. 
Laudon, Kenneth C. Laudon, Jane P. "Management Information Systems: Managing The Digital Firm, Twelfth Edition.” New Jersey: Prentice Hall Inc., 2012.

Ling, Ay. "Pengelolaan Dan Pengembangan Usaha Pada Usaha Mikro Kecil Menengah (Studi Deskriptif Pada Rumah Makan Palem Asri Surabaya. Agora: Vol. 01 . No. 01, 2013.

Moleong, Lexy. J. Metode Penelitian Kualitatif. Bandung: PT Remaja Rosdakarya Cet. XXVI, 2009.

Muflih, Muhammad dan Diharpi Herli Setyowati. "Aplikasi Sistem Keuangan Musyarakah Mutanaqishah sebagai Instrumen Permodalan UMKM di Indonesia" dalam eL-Qist: Journal of Islamic Economics and Business (JIEB) Vol. 5 No. 2 Oktober (2015)

Mulyani, Sri. Metode Analisis dan Perancangan Sistem. Bandung : Abdi Sistematika, 2016

Nababan, Halim. Keamanan Pangan di Kantin Sekolah. Jakarta: Direktorat Survei dan Penyuluhan Keamanan Pangan Deputi Bidang Pengawasan Keamanan Pangan dan Bahan Berbahaya BPOM RI, 2012.

Nuraida, Lilis. Dkk. Menuju Kantin Sehat di Sekolah. Jakarta: Direktorat Jenderal Pendidikan Dasar Kementerian Pendidikan Nasional, 2011.

Porter, Michael. E. Strategi Bersaing: Teknik Menganalisis Industri dan Pesaing. Terjemahan Agus Maulana. Jakarta: Erlangga, 1997.

Puji, Indah. Buku Praktis Mengembangkan SDM, Jogjakarta: Laksana, 2014.

Purwaningsih, Erisva Hakiki. Dkk. Rencana Pengembangan SDM TIK di Indonesia melalui Sertifikasi SKKNI Bidang KOMINFO. Jakarta: Puslitbang SDPPI, Kementerian Komunikasi dan Informatika, 2018.

Rangkuti, Freddy. Analisis SWOT Teknik Membedah Kasus Bisnis, Jakarta: Gramedia Pustaka Utama, 2008.

Satori, Djam'an. dan Komariah, Aan. Metodologi Penelitian Kualitatif. Bandung: Alfabeta CV, 2011.

Setiaji, Rifki Danang. "Petunjuk Teknis Bantuan Pemerintah bagi Wirausaha Pemula 2019. Diakses pada http://pembiayaan.depkop.go.id/index.php/public/regulasi pada oleh Kementerian Koperasi dan UKM Deputi Bidang Pembiayaan pada 18 Mar 2019.

Sudaryanto, Ragimun. Wijayanti, R.R. "Strategi Pemberdayaan UMKM menghadapi Pasar Bebas Asean". Jakarta: Jurnal Pusat Kebijakan Ekonomi Makro, Badan Kebijakan Fiskal Kementerian Keuangan, 2013.

Sukmadinata, Nana Syaodih. Metode Penelitian Pendidikan. Bandung: PT. Remaja Rosdakarya, 2011.

Sutabri, Tata. Analisis Sistem Informasi. Yogyakarta: CV. Andi Offset, 2012.

Terry, G. R . Prinsip-prinsip Manajemen, Jakarta: PT. Bumi Aksara, 2004.

World Economic Forum. "The Global Human Capital Report 2017 Preparing People for The Future of Work" dalam https://doi.org/ISBN 978-194483510-1. 